\title{
A NOÇÃ̃ DE OPINIÃo FALSA À LUZ DE UMA INTERPRETAÇÃ̃o Do NÃO-SER: UM PROBLEMA ENTRE O TEETETO E O SOFISTA DE PLATÃO
}

\author{
Aurelio Oliveira Marques ${ }^{1}$ \\ Universidade de Brasília (UnB) \\ (iD) https://orcid.org/0000-0001-6392-7231 \\ E-mail: amigos.aurelio@gmail.com
}

\section{RESUMO:}

Embora o Teeteto nos coloque num cenário interpretativo completamente à parte da teoria das Formas, não nos é permitido admitir seu total esquecimento. Conceitos como 'racionalidade' contraposto à percepção sensível, e a 'imprescindibilidade do logos' enquanto discurso que perfaz o conhecimento verdadeiro, são extremamente caros ao Teeteto. Desconsiderar a pertinência e a similaridade do significado destes conceitos desde a maturidade até à velhice, colocar-nos-ia em situação de grande dificuldade explicativa acerca do conhecimento. Assim, é importante destacar que optamos por uma perspectiva intermediária, que por um lado reconhece a ausência de uma argumentação calcada na clássica teoria das Ideias, mas que compreende a obra platônica sob a tutela de uma interpretação sistemática e holística, segundo a qual Platão não abandona os pressupostos metafísicos das Formas inteligíveis. Longe de uma ruptura com o que foi dito anteriormente na maturidade, o Teeteto serve como complementação teórica acerca da ontologia e da epistemologia, embora no Teeteto não haja uma menção direta às noções presentes nos diálogos anteriores e boa parte do tema se apresente por meio de estilo de escrita e vocabulário inusitados. Por fim, mas não menos importante, será feita uma breve análise de alguns trechos dos momentos finais do Sofista com o objetivo de compreender em que medida o aspecto epistemológico, proposto por Platão no Teeteto, pode ser lido à luz de questões relacionadas ao Ser e ao Não-ser, já que a pergunta pelo 'o que é conhecimento' nos remete também a uma discussão ontológica.

PALAVRAS-CHAVE: Epistemologia; Ontologia;.Falsidade; Não-ser; Autocrítica.

\section{THE NOTION OF FALSE OPINION IN THE LIGHT OF AN INTERPRETATION OF NON-SER: A PROBLEM BETWEEN THE THEAETETUS AND SOPHIST OF PLATO}

\begin{abstract}
:
Although the Theaetetus puts us in an interpretive setting completely apart from the theory of Forms, we are not allowed to admit their total forgetfulness. Concepts such as 'rationality' opposed to sensible perception, and 'the indispensability of logos' as a discourse that makes true knowledge, are extremely dear to the Theaetetus. Disregarding the relevance and similarity of the meaning of these concepts from maturity to old age would put us in a situation of great difficulty in explaining knowledge. It is important to emphasize here that we have chosen an intermediate perspective, which on the one hand recognizes the absence of an argument based on the classical theory of Ideas, but which includes the Platonic work under the tutelage of a systematic and holistic interpretation, according to which Plato does not abandon the metaphysical presuppositions of the intelligible Forms. Far from a rupture with what was said earlier in maturity, the Theaetetus serves as a theoretical complementation on ontology and epistemology, although in the Theaetetus, as we have said, there is no direct reference to the notions present in previous dialogues and much of the theme introduce yourself through unusual writing style and vocabulary. Last but not least, a brief analysis will be made of some passages from the final moments of the Sophist in order to understand to what extent the epistemological aspect, proposed by Plato in the Theaetetus, can be read in the light of questions related to Being and to Not-being, since the question of 'what is knowledge' also leads us to an ontological discussion.
\end{abstract}

KEYWORDS: Epistemology; Ontology; Falsity; Not-being; Self-criticism.

${ }^{1}$ Doutorando em Filosofia na Universidade de Brasília (UnB), Brasília - DF, Brasil.

MARQUES, Aurelio Oliveira. A noção de opinião falsa à luz de uma interpretação do não-ser: um problema entre o Teeteto e o Sofista de Platão. Griot : Revista de Filosofia, Amargosa-BA, v.19, n.2, p.122-134, junho, 2019. 


\title{
Considerações iniciais
}

No Teeteto, uma das principais obras platônicas de transição entre o fim da maturidade e começo da velhice, Platão tem por principal objetivo abordar o tema do conhecimento sob uma perspectiva essencialista; ou seja, o objetivo de Platão não é descrever a variedade de conhecimentos existentes, mas buscar conceitualmente o que seria o conhecimento em si, compreendido sob o prisma de sua universalidade. Utilizando-se da maiêutica, método capaz de fazer o interlocutor conceber ideias acerca de determinado tema, Sócrates faz o jovem matemático Teeteto definir conhecimento de três modos no decorrer da obra: (1) como sensação; (2) como opinião verdadeira; (3) como opinião verdadeira acompanhada de explicação racional. Vale ressaltar ainda que a obra em questão, além de abordar o tema do conhecimento de modo preciso, também pode ser lida sob a perspectiva de uma filosofia da linguagem. Apesar disso, viso a salientar neste trabalho uma interpretação epistemológica, isto é, relacionada à natureza, à origem e ao alcance do conhecimento humano - temas estes bastante caros à história da filosofia como um todo.

Um dos aspectos mais discutidos acerca do Teeteto é se esta obra demarca o abandono ou a reafirmação da clássica teoria das Ideias de Platão. Com efeito, no decorrer da história da filosofia, duas correntes epistemológicas se construíram, de modo que uma se opõe diretamente à outra: (1) há uma tendência conservadora, segundo a qual o Teeteto consistiria no endossamento da clássica teoria das Ideias ao modo como já tinha sido descrita nos diálogos de maturidade, e a exemplo disso podemos mencionar o Fédon e a República. Em defesa dessa perspectiva temos, notadamente, as obras de Ross (1966) e de Conford (1935). (2) Doutro modo, há uma tendência radical, segundo a qual, a partir dos diálogos de transição entre o fim da maturidade e o período tardio, tais como Parmênides e Teeteto, Platão teria abandonado por completo seu clássico viés epistemológico acerca da teoria das Ideias. Em defesa desta perspectiva podemos mencionar o trabalho de Gilbert Ryle (1966). Acerca desta distinção cito Santos:

\begin{abstract}
Achamo-nos, portanto, perante duas alternativas: aceitar ou rejeitar a presença de Formas no argumento e até no texto do diálogo. A dificuldade reside na circunstância de nenhuma das alternativas mais conhecidas (Cornford e Ryle) nos parecer satisfatória. Uma, por condicionar toda a compreensão do diálogo à aceitação de um pressuposto implícito; a outra, pelo facto de a subordinar a uma interpretação global da filosofia platónica, totalmente infundada. A proposta que apresentaremos passa pela anulação da alternativa, deixando ao leitor a liberdade de aceitar ou rejeitar a presença de Formas, sem condicionar a sua compreensão do diálogo. Mas essa estratégia implicará renunciar à abordagem do diálogo como veículo doutrinal. (SANTOS, 2010. p. 10).
\end{abstract}

Acerca da cronologia de obras platônicas pode-se afirmar que, até meados do século XIX, os estudos possuíam um aspecto puramente interpretativo, ou seja, versavam tão somente sobre as noções contidas em cada obra, a fim de encontrar congruências e mudanças no pensamento do autor para se estabelecer a ordem de aparecimento delas. Apesar de ter sido um esforço útil, esse tipo de abordagem não 
reuniu muitas informações, e as poucas encontradas não foram suficientes para se estabelecer um caminho seguro acerca da cronologia.

Lewis Campbell - um antigo professor de grego da Universidade de St. Andrews (Escócia) - deu início a uma abordagem estilística, no final do século XIX, ao observar características linguísticas presentes em dois diálogos também traduzidos por ele, a saber, o Sofista e o Político. Sua análise compreendia tanto os aspectos interpretativos das obras quanto a verificação da repetição de termos técnicos e, até mesmo, da variação rítmica. Já no século XX, esse tipo de abordagem foi aprimorado e várias pesquisas de cunho estilométrico contribuíram para estabelecer a divisão do pensamento platônico em três ou quatro grandes períodos, ainda que não resolvesse as falhas acerca da cronologia interna de cada um deles. (CAMPBELL, 1861, p. xv).

Para Lopes, a estilometria possui uma série de limitações. Dentre elas, podemos citar o fato de que tais estudos ressaltam os aspectos internos dos diálogos deixando de lado, por muitas das vezes, fatos históricos e testemunhos de pessoas do convívio de Platão. Outro grande problema é do parâmetro inicial utilizado para fazer a análise das demais obras. Assim, é quase impossível atribuir uma datação precisa dos diálogos, o que acaba por impossibilitar também a compreensão de uma possível mudança ou modificação acerca do estilo de escrita de Platão. Ademais, Lopes afirma que há outros dois aspectos totalmente ignorados por aqueles que se engajaram na análise estilométrica das obras platônicas: a primeira delas é que tais estudos não consideram a possibilidade de Platão ter revisto os próprios textos e, portanto, não consideram que exista uma data inicial de escrita e uma data final de edição. O segundo aspecto ignorado é o da possibilidade de Platão ter feito modificações intencionais, isto é, escrever propositadamente com estilo distinto. Ao fim de sua argumentação, Lopes admite que, embora o estudo estilométrico acerca da cronologia dos diálogos não seja suficiente, tal abordagem consiste num marco histórico que tornou praticamente consensual a divisão dos diálogos em três grandes grupos: juventude, maturidade e velhice. (LOPES, 2018, pp.95-97).

Segundo Cornford, Platão não deixa dúvida nenhuma acerca da ordem que devemos ler os diálogos: Parmênides, Teeteto, Sofista e Político. Tanto o Teeteto (183e) quanto o Sofista (217c) fazem referência ao Parmênides, o que nos permite supor com certa precisão sua antecedência. De modo semelhante, os momentos finais do Teeteto anunciam que a discussão continuará em um momento posterior, momento esse que dá início à narrativa do Sofista. Já o Político faz menção direta ao Sofista, pois um é continuação da conversação do outro. Isso também evidencia a cronologia proposta acima. Apesar disso, Cornford observa que no decorrer da história da filosofia as investigações acerca da cronologia, mais especificamente acerca do Teeteto, revelam que a obra inicia-se com um estilo de escrita e, ao final, possui um estilo distinto, mais bem elaborado. Essa mudança de estilo deixa claro que Platão, no decorrer de sua vida, foi agregando novas estruturas linguísticas, o que impactou diretamente em seus diálogos. Partindo disso, Cornford defende a ideia de que o Teeteto demorou longos anos para ser escrito, e que o Parmênides foi escrito justamente neste intervalo de tempo, entre o estilo inicial de escrita do Teeteto e o estilo final. (CONFORD, 1935, p.1). 
De todo modo, apesar de considerarmos importante essa composição cronológica, não nos limitamos a discutir a ordem em que as obras platônicas de transição foram escritas, mas temos por principal objetivo fazer uma cuidadosa análise do Teeteto. Neste sentido, a obra em questão apresenta-se como uma das principais acerca do problema do conhecimento ou, por melhor dizer, acerca da natureza da própria ciência (episteme).

\section{Da relação entre "não-ser" e "falsidade"}

No Sofista, entre 259d e 264b, a questão epistemológica acerca da possibilidade de concebermos falsas opiniões é encaminhada sob a tutela de uma argumentação ontológica. O Teeteto, embora tenha dado início a esta investigação, não obteve completo êxito, porque exclui as Formas, não mencionando as mesmas na discussão que apresenta. Antes de adentrarmos na questão acerca do não ser, é importante destacar que, no Sofista, a origem do discurso (logos) se dá a partir da mútua combinação (simploke) das Formas (eidos). Essa combinação é consequência da comunhão (koinonia) ${ }^{2}$ de todas as coisas no Ser (on). A este propósito, cito Borges:

É comum supor que os problemas da segunda parte do Teeteto são resolvidos no Sofista. Argumenta-se, corretamente, que no Teeteto e no Sofista Platão parece estar envolvido com questões ligadas à forma como se deve explicar a relação entre a alma e os objetos conhecidos por ela. Uma destas questões é o problema da falsidade. Platão demonstra no Teeteto 187c-201d e no Sofista - na seção que Moravcsik chama em sua obra Platão e Platonismo (2006) de 'ensaio sobre o discurso' (a partir de 259e) - uma percepção apurada da insuficiência das posições que procuram descrever a estrutura do falso, sobretudo das posições que negam sua existência Em geral as doutrinas gregas assimilam a opinião falsa ao não-ser. (BORGES, 2009, p. 80).

Como afirma Cornford, embora o Sofista sugira que o discurso tenha sua origem a partir da combinação (simploke) das Formas (eidos), não nos é permitido admitir que as Formas sejam os únicos elementos no significado de todo o discurso. Também podemos fazer enunciados sobre coisas individuais. No entanto, todo enunciado deve conter pelo menos uma Forma, um daqueles termos comuns necessário a todo pensamento ou juízo sobre os objetos da percepção direta. Ademais, afirma que a importância de destacar todo juízo como constituído a partir de pelo menos uma Forma consiste no fato de que o reconhecimento das Formas enquanto constituintes do significado de todos os enunciados resolverá o problema do discurso (logos) e do pensamento (dianoia) falsos. (CORNFORD, 1935, pp. 300$301)$.

\footnotetext{
${ }^{2} \mathrm{Na}$ Grécia Antiga, este conceito estava, em geral, relacionado aos laços responsivos que os cidadãos iguais possuíam entre si, ou seja, dizia respeito aos aspectos comunitários de determinada coletividade. No Sofista, o termo aparece para significar que o discurso filosófico racional (logos), que dá origem ao conhecimento (episteme) é proveniente de um entrelaçamento (simploke) entre as Ideias inteligíveis (eidos). No diálogo em supracitado, Platão não descreve apenas a relação vertical existente entre o sensível e o inteligível, entre coisas múltiplas e a unidade, mas faz um cuidadoso estudo acerca das relações que os próprios inteligíveis estabelecem entre si. Em suma, koinonia é, em profundo sentido, a comunhão, o compartilhamento mútuo que uma Ideia (eidos) estabelece com as demais para que um discurso (logos) possa ter real significado.
}

MARQUES, Aurelio Oliveira. A noção de opinião falsa à luz de uma interpretação do não-ser: um problema entre o Teeteto e o Sofista de Platão. Griot : Revista de Filosofia, Amargosa - BA, v.19, n.2, p.122-134, junho, 2019. 
ESTRANGEIRO. - Muito bem; resta-nos agora examinar se ele [o nãoser, me on] se associa à opinião (doxa) e ao discurso (logos).

TEETETO. - Por quê?

EST. - Se ele não se associa, segue-se necessariamente que tudo é verdadeiro. Mas, uma vez que ele se associe, então, a opinião falsa e o discurso falso serão possíveis. $O$ fato de serem não-seres o que se enuncia ou se representa, eis o que constitui a falsidade, quer no pensamento (dianoia), quer no discurso (logos).

TEE. - Com efeito.

EST. - Ora, se há falsidade, há engano.

TEE. - Sim.

EST. - E desde que há engano, há em tudo, inevitavelmente, imagens (eikonon), cópias (eidolon) e simulacros (phantasias).

TEE. - Naturalmente.

EST. - Ora, como dissemos, é exatamente nesse abrigo que o sofista se refugiou, e, uma vez ali negou obstinadamente a própria existência da falsidade. A seu ver, ninguém há que conceba ou que enuncie o não-ser; pois o não-ser não possui, sob relação alguma, parte nenhuma do ser.

TEE. - Foi exatamente essa sua atitude. (PLATÃO. Sophistes $260 \mathrm{c}-\mathrm{d}$, 1983, pp. 185-186).

Dando prosseguimento à investigação, o Estrangeiro, personagem que junto a Teeteto se esforça por investigar a definição de sofista, propõe que seja estudado o modo pelo qual surge o engano e a falsidade no discurso (logos) ou mesmo no pensamento (dianoia). Com efeito, o sofista - que desde o início do diálogo vinha sendo definido como caçador interesseiro de jovens ricos (223b), como comerciante de saberes (224d), como erístico mercenário (226a) e como refutador (231b) - é também alguém que nega veemente a possibilidade do engano acerca da concepção de juízos (doxa). Para o sofista, a alma é capaz de conceber tão somente opiniões verdadeiras. No entanto, os interlocutores acabam por verificar que o conhecimento das Formas inteligíveis confere aos enunciados falsos um significado (semeion), sem que seja necessário recorrer a coisas não existentes. $O$ Estrangeiro observa que o ponto inicial da investigação consiste no fato de que 'dizer o que é falso' é, em certo sentido, 'dizer coisas que não são' (to ta me onta legein). O principal problema aqui é apreender de modo satisfatório o significado destas 'coisas que não são'. Cito Santos:

O problema de 'o que não é' só é solucionado com a introdução do NãoSer. Constituindo o quinto Sumo gênero e apoiado na reformulação do sentido da negativa, que, de 'contrário' passa a significar o 'diferente' (257b-c), o Outro faz do Não-Ser ‘um outro Ser'. (SANTOS, 2018, p. 161).

Platão, no Sofista, sugere que 'aquilo que não é' nem sempre se coaduna e se limita ao 'não existente', pois pode ser o caso de significar uma diferença (to heteron). Por exemplo, ao dizermos que 'esta parede não é vermelha' estamos significando algo que é diferente de alguma outra coisa. De todo modo, esses dois 'algos', (1) o que é o mesmo (to tauton) e (2) o que é outro (to heteron), passam a possuir determinação ontológica, pois não podem ser considerados nada (medeis), já que são algo (on). No entanto, isso gera uma profunda ambiguidade entre ser e não-ser. Assim, ambos os interlocutores, Estrangeiro e Teeteto, dão novo encaminhamento à discussão a fim 
de descortinar este problema investigando se o não-ser (me on) associa-se, de algum modo, à opinião (doxa) e ao discurso (logos) tornando-lhes falsos.

\begin{abstract}
Sabemos agora que o Ser é o Tudo e o Todo, envolvendo os outros Todos. A circunstância de estes não contarem como suas partes constitui a definitiva resolução do problema da 'participação'. Todo o argumento vista o objectivo último de desmascarar a estratégia refutativa atribuída ao sofista, condensada na tese, geradora de aporias, da impossibilidade da falsidade e da contradição (240a-b). Para tal, será ainda necessário combinar o Não-Ser com a opinião e o discurso em 260b. (SANTOS, 2018, p. 163).
\end{abstract}

Se bem observarmos os momentos subsequentes do Sofista, poderemos constatar que boa parte da argumentação apresentada se fundamenta numa filosofia da linguagem, na qual os termos que compõe um enunciado, isto é, nomes (onoma) e verbos (rema), são levados em consideração à luz do conceito de comunhão (koinonia), que é responsável por ligar as coisas ao Ser (on). Os interlocutores chegam à conclusão parcial de que não bastam às letras, aos nomes e aos verbos estarem dispostos de modo aleatório; é necessário, antes, que formem sentido (semeion). Uma lista de nomes (leão, cervo, cavalo) ou ainda uma lista de verbos (anda, corre, dorme) são incapazes de formar sentido e darem origem a um discurso. Segundo o Estrangeiro, um discurso surge do entrelaçamento (simploke) não casual de nomes e verbos. Observam, ademais, que todo discurso é sempre acerca de alguma coisa, pois sobre o nada (medeis) é impossível haver discurso (logos). Quando enunciamos um discurso o fazemos juntamente com uma qualidade determinada, que é ou verdadeira ou falsa (263b). Acerca disso, o Estrangeiro dá dois exemplos: (1) 'Teeteto está sentado' (2) 'Teeteto, com quem agora converso, voa'. Ambos os interlocutores estabelecem que a pessoa da qual se fala, nos dois discursos, é Teeteto, mas a qualidade de cada um destes enunciados é diferente, pois o primeiro é verdadeiro e o segundo é falso. Aquilo que é verdade a respeito de Teeteto diz o que é tal como é, ao passo que aquilo que é falsidade a respeito de Teeteto diz aquilo que não é. A meu ver, Platão parece esforçar-se aqui por apresentar não apenas noções lógicas sob as quais operam a linguagem, mas também uma noção epistemológica da verdade enquanto correspondência. Ou seja, o discurso emitido será verdadeiro se, de fato, versar sobre a realidade que está sendo dita; mas, caso o discurso não se coadune com a realidade descrita, deve ser considerado falso.

ESTRANGEIRO. - E aquele que é falso diz outra coisa que aquela que é.

TEETETO. - Sim.

EST. - Diz, portanto, aquilo que não é.

TEE. - Mais ou menos.

EST. - Ele diz, pois, coisas que são, mas outras (heteros), que aquelas que são a teu respeito; pois, como dissemos ao redor de cada realidade há, de certo modo, muitos seres e muitos não-seres.

TEE. - Certamente. (PLATÃO. Sophistes 263 b - c, 1983, p. 189).

Segundo Filho, algo que deve merecidamente ser destacado nesta passagem é a resposta de Teeteto. Quando o jovem geômetra responde de modo inseguro à questão posta pelo Estrangeiro, o argumento ontoepistemológico de que a falsidade 
enquanto não-ser equivale a não existir cai por terra. Com efeito, o Estrangeiro revela que a condição para a definição do enunciado falso acaba por abarcar o raciocínio da alteridade, pois afirmamos o ser por meio de outras coisas em relação ao nosso referente. (FILHO, 2008. pp. 85-86).

Só o Sofista superará todas as dificuldades apesentadas nos diálogos anteriores. Platão começa por criticar os "amigos das Formas" propondo a correção do dualismo ontoepistemológico que opõe a "geração à entidade" (genesis - ousia), contrapondo o Saber à Opinião. A nova abordagem rejeita a identidade - eleática e platônica - do Saber ao Ser, analisando em termos distintos a "fusão" dos três índices distintivos que caracterizam a doxa como competência cognitiva: "crença, aparência e opinião". Todavia, a inovação que libera a pesquisa da constrição imposta pela argumentação eleática (simultaneamente desmontando a cadeia de aporias a que os sofistas a submetem) manifesta-se na reformulação do sentido "negativa", que, de "contrariedade", passa a ser lida como "diferença". Antes ainda de ser expressamente registrada no diálogo, é ela que permite que o Não-Ser venha a poder ser encarado como "outro" em relação ao Ser, existindo não menos que ele. (SANTOS, 2017, p. 14).

Com efeito, o discurso falso surge quando se diz algo outro (heteros) do que de fato é, e quando dizemos o que não é o mesmo (autos) como sendo (onta). $\mathrm{O}$ fato de dizer 'outra coisa que aquilo que é' difere ligeiramente de 'dizer aquilo que não existe (me on)', pois dá-se o caso de que quem diz algo que não está factualmente relacionado a alguém, diz 'algo outro (heteros)' daquilo que efetivamente está relacionado à pessoa de quem se diz. No que concerne à minha interpretação, não devemos compreender esta negação imperativa (me) como contrária (enantion) ao ser. O me surge como movimento (dinamis) que inclui 'sim' e 'não', simultaneamente. Assim, o me deixa de ser meramente uma partícula excludente e contraditória do ser, passando a demonstrar e nos fazer ver algo que é outro (heteros) por um via holística. É deste modo que afirmamos acima que a negativa do ser deve ser vista não como contrariedade, mas como alteridade.

ESTRANGEIRO. - Desde que há, como vimos, discurso (logos) verdadeiro e falso, e que, no discurso, distinguimos o pensamento (dianoia) que é o diálogo da alma consigo mesma, e a opinião, que é a conclusão do pensamento, e esse estado de espírito que designamos imaginação (phantasia), que é a combinação da sensação (aisthesis) e opinião (doxa), é inevitável que, pelo seu parentesco com o discurso, algumas delas sejam, algumas vezes, falsas.

TEETETO. - Naturalmente.

EST. - Percebes como descobrimos a falsidade da opinião e do discurso bem mais prontamente do que esperávamos, quando, há bem pouco, receávamos perder o nosso trabalho, empreendendo tal pesquisa?

TEE. - Sim percebo. (PLATÃO. Sophistes 264 a - e, 1983, p. 190).

No Sofista é estabelecido que pensamento (dianoia), opinião (doxa) e imaginação (phantasia) são gêneros suscetíveis nas almas tanto da falsidade quanto da verdade. Pensamento (dianoia) e discurso (logos), segundo o Estrangeiro, são a mesma coisa; a principal diferença é que o primeiro diz respeito ao diálogo silencioso da alma consigo mesma, ao passo que aquilo que emana da alma e emitimos

MARQUES, Aurelio Oliveira. A noção de opinião falsa à luz de uma interpretação do não-ser: um problema entre o Teeteto e o Sofista de Platão. Griot : Revista de Filosofia, Amargosa-BA, v.19, n.2, p.122-134, junho, 2019. 
vocalicamente dá-se o nome de discurso. Ademais, opinião (doxa) se distingue ligeiramente de imaginação (phantasia). A primeira se dá quando na alma, em reflexão silenciosa, surge afirmação ou negação. A segunda, quando a afirmação ou a negação chega por intermédio da sensação (aisthesis).

\section{Conclusões parciais}

De modo sucinto, a única coisa que se pode concluir de tudo isso é que a discussão acerca das opiniões falsas é aporética. Isso se dá deste modo porque Sócrates e Teeteto chegam a conclusão parcial de que é impossível conhecer a pseudes doxa sem saber antes o que é conhecimento (episteme). Apesar disso, a investigação acerca desse problema foi extremamente útil para nos distanciar dos meios pelos quais não adquirimos tais opiniões. Depois de terem debatido longamente em relação a esse tema e não terem alcançado sucesso, Sócrates e Teeteto voltam a ocupar-se da pergunta inicial, a saber, se conhecimento é opinião verdadeira. A resposta a esse questionamento é quase que imediata no diálogo. Segundo Sócrates, não é possível coadunarmos alethes doxa com episteme porque a primeira se ocupa do discurso persuasivo, próprio dos oradores e dos advogados, ao passo que a segunda se apresenta sempre com clareza e exatidão diante de nós. Explica que os advogados não se utilizam de saberes ou de conhecimentos (episteme) para convencer seus ouvintes, mas sempre persuadem através de sugestões (doxa), que nada mais são que meras opiniões. Ademais, num tribunal, o juiz não leva em consideração apenas a testemunha, mas todos os elementos presentes no julgamento. Assim, a persuasão do advogado será bem-sucedida se as sugestões dadas acerca de um fato forem suficientemente capazes de conquistar a confiabilidade do juiz. É impossível que um juiz tenha certeza dos fatos e, portanto, seu veredito nunca será completamente assertivo. Dito de outro modo, a decisão de um juiz é proveniente das sugestões, ou seja, das opiniões que lhe são apresentadas acerca de determinado fato. Deste modo, é igualmente impossível que seu julgamento seja proveniente da episteme mas é certo dizer que tem seu fundamento na doxa, ou seja, no fato de estar persuadido de algo. É justamente por isso que conhecimento não pode jamais se coadunar com a noção de opinião verdadeira, e menos ainda sê-la.

Segundo David Sedley, diversos aspectos presentes na segunda definição que Teeteto dá a Sócrates como resposta à pergunta pelo ‘o que é conhecimento' ficaram incorporados dentro da história da filosofia, dentre eles a análise do pensamento como discurso interno e o modo pelo qual percepção e memória se relacionam. Ademais, a explicação acerca da aquisição do conhecimento passa a ter uma nova roupagem. A substituição da teoria da cera pela teoria do aviário é algo que enfatiza a interpretação que Platão dá ao mundo físico em seus diálogos tardios. (SEDLEY, 2002, pp. 151-152).

Segundo Copleston, nenhum dos diálogos platônicos se ocupa em expressar sistematicamente a teoria do conhecimento. O que o Teeteto faz é apresentar problemas trazendo, em cada uma de suas partes principais, conclusões negativas. Dito de outro modo, o Teeteto não é uma obra para afirmar o que é conhecimento, mas para dizer o que não é, principalmente no que concerne à percepção sensível. Uma abordagem positiva acerca do tema, isto é, que afirme o significado de

MARQUES, Aurelio Oliveira. A noção de opinião falsa à luz de uma interpretação do não-ser: um problema entre o Teeteto e o Sofista de Platão. Griot : Revista de Filosofia, Amargosa - BA, v.19, n.2, p.122-134, junho, 2019. 
conhecimento, encontra-se na República, obra de maturidade em que Platão apresenta os graus de conhecimento. Para Copleston, é demasiado errôneo dizermos que Platão, no Teeteto, tem por objetivo mudar completamente seu pensamento acerca do conhecimento. Seu objetivo, na obra em questão, consiste em fazer uma revisão crítica acerca das dificuldades encontradas no contexto em que ela se insere a fim de refutar sistematicamente as teorias que considerava falsas. (COPLESTON, 1993, pp. 142-143).

Por último, é no Teeteto onde Platão melhor expõe as bases sob as quais apoia sua teoria das Ideias. Esta está embasada na crença de que há uma completa distinção entre sensação e conhecimento; e de que o conhecimento requer objetos e entidades não percebidas pelos sentidos (Teeteto, 151d - 186e). É no Teeteto, assim como Timeu (51d - e), que Platão também demarca a distinção entre opinião verdadeira e conhecimento (Teeteto, 187a - 210b). Assim, ainda que o diálogo não se ocupe estritamente de metafísica, mas de epistemologia, proporciona o mais sólido argumento que Platão nunca antes tinha concebido para dar fundamentação à sua teoria metafísica. (ROSS, 1966, p. 103).

Em suma, para David Ross, o Teeteto surge na cronologia das obras de Platão como a radicalização de sua compreensão de mundo. É uma intensificação e uma reafirmação de sua clássica teoria das Ideias. A argumentação presente no Teeteto é o que solidifica as bases filosóficas de Platão, tornando-a mais firme para que ele possa dar prosseguimento à distinção entre sensibilidade e inteligibilidade já demarcada em sua República.

É certo dizer que o diálogo é aporético, mas a que isso se deve? Por ora, se deixarmos de lado a questão fundamental de se Teeteto é ou não uma reafirmação do que já foi dito por Platão em sua República, e nos atermos ao aspecto aporético do diálogo, no que concerne à minha interpretação, defendo que, possivelmente, a ausência de uma menção à teoria das Ideias nos coloca em tal problema. Acredito veemente que a aporia aqui se deu em razão da não explicitação da teoria das Ideias. A meu ver, é impossível chegar a uma definição fixa e imutável sem antes reconstruirmos a teoria das Formas como fundamento de toda a investigação. Percebo que Platão, em alguns momentos do Teeteto, nos faz pensar na teoria das Formas ainda que de modo indireto. Apesar disso, o esforço interpretativo retirado do cenário no qual ele nos coloca não é suficiente para nos fornecer uma resposta clara e distinta acerca do que seja episteme Acredito também que se houvesse uma referência direta à teoria das Ideias isso possibilitaria uma definição mais precisa e o diálogo, certamente, tomaria outras dimensões. Por outro lado, a obra em questão nos permite ver com outros olhos as justificativas pelas quais Platão recusa a tese de que o conhecimento advenha da sensibilidade. Diferentemente de seus diálogos de maturidade, Platão faz aqui um profundo estudo acerca da percepção humana definindo, assim, seu grau de importância para o conhecimento em geral. Isto se dá deste modo não apenas sob o aspecto pontual que o assunto ocupa, mas sob a tutela de uma reconstrução histórica do pensamento de alguns de seus predecessores, nomeadamente Protágoras e Heráclito. É por meio dessa crítica que Platão afirma a impossibilidade de se definir conhecimento como sensação, e passa a atribuir tal investigação ao âmbito racional, estabelecendo a existência de objetos específicos que

MARQUES, Aurelio Oliveira. A noção de opinião falsa à luz de uma interpretação do não-ser: um problema entre o Teeteto e o Sofista de Platão. Griot : Revista de Filosofia, Amargosa - BA, v.19, n.2, p.122-134, junho, 2019. 
dependem estritamente da alma para serem conhecidos. Cito Copleston:

\begin{abstract}
A conclusão que se deve retirar não é a de que nenhum conhecimento se alcança com a definição feita mediante uma diferença, mas de que o objeto individual, sensível, é indefinível e não é, na realidade, o objeto próprio do conhecimento. Esta é a genuína conclusão do Diálogo, a saber, que o conhecimento verdadeiro dos objetos sensíveis está fora do nosso alcance, e que, portanto, o verdadeiro conhecimento há de versar sobre o universal e o permanente. (COPLESTON, 1993, p.149).
\end{abstract}

Desde o início do Teeteto, Platão tem chamado a atenção para duas características do conhecimento: sua infalibilidade e seu supremo grau ontológico de realidade. Todo estado da alma que reivindique o verdadeiro conhecimento e deseje de fato conhecê-lo não pode jamais concluir tal tarefa se deixar de lado estas duas características supracitadas. Nem a percepção sensível, nem a opinião verdadeira, nem a opinião verdadeira acompanhada de explicação racional são condizentes com a noção essencial de conhecimento. Isso se dá deste modo porque nenhuma destas definições apreendem completamente o Ser (on). De Protágoras, Platão aceita a relatividade acerca da percepção sensível, pois esta é para cada um segundo o seu aparato sensorial. No entanto, recusa a relatividade universal acerca do conhecimento. Para Platão, o verdadeiro conhecimento é absoluto, infalível e pode ser alcançado, mas nunca por meio dos sentidos, pois estes estão submetidos às influências momentâneas que sofrem os sujeitos e também os objetos. De Heráclito, Platão aceita a noção de que a percepção sensível, a sensibilidade e os objetos particulares estão em constante fluxo e, por isso, não podem nunca serem elevados aos status de conhecimento verdadeiro. No entanto, recusa a ideia de que todas as coisas, sem exceção, estejam em constante mudança. Isto se dá deste modo porque a aceitação completa da tese heraclítica inviabilizaria a própria investigação que a obra pretende cumprir, isto é, a busca por uma definição fixa e universalmente válida de conhecimento.

Em suma, apesar desta segunda parte do Teeteto não nos ter fornecido uma resposta satisfatória acerca da essência do conhecimento, a argumentação aqui desencadeada foi extremamente útil para demarcar bem a importância do processo intelectivo na busca pelo saber (episteme), afastando-nos mais ainda da sensação (aisthesis). Com efeito, a investigação aqui presente serviu para deixar de lado a noção de conhecimento como sendo opinião em geral, visto existirem opiniões falsas. Num nível posterior da argumentação, passou-se a examinar os modos pelos quais não adquirimos falsas opiniões, pois é impossível conhecer a pseudes doxa sem que se tenha definido antes o que propriamente é conhecimento. Ademais, reconstruímos a argumentação de que o conhecimento não pode se coadunar com a noção de opinião verdadeira (alethes doxa), visto que é a persuasão, a retórica própria de oradores e advogados, que nos fazem admitir por meio de sugestões (doxa) algumas coisas como supostamente certas e verdadeiras, e não por meio do conhecimento (episteme).

Por fim, mas não menos importante, vale ressaltar que foi feito uma breve análise de alguns trechos pertencentes aos momentos finais do Sofista, a fim de compreender, em parte, o desfecho do aspecto metafísico da teoria platônica das Ideias. Tal investigação permitiu uma releitura epistemológica do Teeteto à luz de

MARQUES, Aurelio Oliveira. A noção de opinião falsa à luz de uma interpretação do não-ser: um problema entre o Teeteto e o Sofista de Platão. Griot : Revista de Filosofia, Amargosa - BA, v.19, n.2, p.122-134, junho, 2019. 
questões relacionadas ao Ser (on) e ao não-ser (me on). Em suma, constatamos que não se deve compreender esta negação imperativa (me) como contrária (enantion) ao ser. O me surge como movimento (dinamis) que inclui 'sim' e 'não', simultaneamente. Observamos que o me deixa de ser meramente uma partícula excludente e contraditória do ser, passando a demonstrar algo que é outro (heteros). Deste modo, defendemos que a negativa do ser deve ser interpretada não como contrariedade, e sim como alteridade, porque quando dizemos algo falso não estamos dizendo nada (medeis), mas algo (on). Ademais, há um importante retorno à teoria das Formas compreendidas sob o aspecto do entrelaçamento (simploke) das mesmas e da comunhão (koinonia) de cada uma delas no Ser (on). Isso nos permitiu observar os elementos da linguagem, nomes (onoma) e verbos (rema), como imprescindíveis para o surgimento do discurso (logos). Partindo deste pressuposto, investigamos as implicações da falsidade (pseudes), seja na opinião (doxa) ou no discurso (logos). Entendemos, por fim, que, no Sofista, o discurso falso surge quando se diz 'algo outro (heteros)' do que de fato é, e quando dizemos 'o que não é o mesmo (autos)' como sendo (onta). 


\section{Referências:}

BENSON, Hugh, H. Platão. Trad. Marco Antonio de Ávila Zingano. Porto Alegre: Artmed, 2011.

BOCAYUVA, Izabela. "Entre o Parmênides e o Sofista de Platão". Revista Anais de Filosofia

Clássica, Vol. $8 \mathrm{~N}^{\mathrm{o}}$ 16, 2014. pp. 62-72.

BOERI, M. D. Sensopercepción y estados afectivos. Sobre el valor de la aisthesis en la explicaciónplatónica del conocimiento. In: SANTOS, J. T. (Org). Do Saber ao Conhecimento Estudos sobre o Teeteto. Lisboa: Centro de Filosofia da Universidade de Lisboa, 2005.

BORGES, Anderson de Paula. Razão e sensação no Teeteto de Platão. 2009. Tese (Doutorado em Filosofia) - Faculdade de Filosofia, Letras e Ciências Humanas, Universidade de São Paulo, São Paulo, 2009. doi:10.11606/T.8.2009.tde-22032010121526. Acesso em: 2018-02-02.

BRISSON, Luc e PRADEAU, Jean François. Vocabulário de Platão. Trad. Claudia Berliner. São Paulo: WMF Martins Fontes, 2010.

BURNYEAT, M .F. Introduction au Théétète de Platon. Edição francesa traduzida por Michel Narcy. Paris: PUF 1998.

BURNYEAT, M .F. The Theaetetus of Plato. Cambridge: Hackett Publishing Company, 1990.

CAMPBELL, Lewis. The Theaetetus of Plato. Oxford: Oxford University Press, 1861.

CASERTANO, Giovanni. O lugar e o significado do Teeteto na obra platônica. In: SANTOS, José Trindade (Org). Do Saber ao Conhecimento - Estudos sobre o Teeteto. Lisboa: Centro de Filosofia da Universidade de Lisboa, 2005.

CHAPPELL, T. Reading Plato's Theaetetus. Cambridge: Hackett Publishing Company, 2004.

COPLESTON. Frederick Charles, A history of philosophy. Vol I: Greence and Rome. New York. Ed.: Image Books, Doubleday, 1993.

CORNELLI, Gabriele; LOPES, Rodolfo. Platão. São Paulo; Portugal: Imprensa da Universidade de Coimbra, $1^{\mathrm{a}}$ edição, 2018. Vários autores.

CORNFORD, F. M. Plato's Theory of Knowledge. London: Routledge, 1935.

CROMBIE, Ian. M. Analisis de las Doctrinas de Platon. Trad. A. Torón e Júlio C. Armero. Madrid: Alianza, 1988.

EL MURR, D. (Org.). La mesure du savoir. Études sur le Théétète de Platon. Paris, Vrin, 2013.

FILHO, Francisco de Assis V.C. O problema do não-ser no Sofista de Platão. Universidade Federal da Paraíba. João Pessoa, 2008.

FERRARI, Franco. "Teoria das Ideias". In: Platão. Organizado por Gabriele Cornelli e Rodolfo Lopes. São Paulo; Portugal: Imprensa da Universidade de Coimbra, $1^{\mathrm{a}}$ edição, 2018. Vários autores. pp. 213-228.

FRONTEROTTA, Francesco.. La Teoria Platonica delle Idee e la Partecipazione delle Cose Empiriche: dai Dialoghi Giovanili al Parmenide. Pisa: Scuola Normale Superiore, 2001 .

MARQUES, Aurelio Oliveira. A noção de opinião falsa à luz de uma interpretação do não-ser: um problema entre o Teeteto e o Sofista de Platão. Griot : Revista de Filosofia, Amargosa - BA, v.19, n.2, p.122-134, junho, 2019. 
HAMELIN, Guy. A natureza da virtude como saber em Platão. Journal of Ancient Philosophy, São Paulo, v. 11, n. 1, p. 99-107, 2017. Unicamp, 11 (2), 2004.

LAFRAnCE, Y. La théorie platonicienne de la doxa. Collection d'Etudes Anciennes. Coll. Noesis. Montréal/Paris: Les Belles Lettres / Bellarmin, 1981.

LAFRANCE, Y. "Le Platon de Gilbert Ryle". In: Revue Philosophique de Louvain. Quatrième série, tome $69, \mathrm{n}^{\circ} 3,1971$. pp. 337-369

LALANDE, André. Vocabulário Técnico e Crítico da Filosofia. Trad. Fátima Sá Corrêa et alli. São Paulo: Ed.: Martins Fontes, 1999.

LOPES, Rodolfo. "Ordenação dos Diálogos". In: Platão. Organizado por Gabriele Cornelli e Rodolfo Lopes. São Paulo; Portugal: Imprensa da Universidade de Coimbra, $1^{\text {a }}$ edição, 2018. Vários autores. pp.79-99.

PLATÃO. Sophistes. Coleção os pensadores. Tradução de José Cavalcante de Sousa, Jorge Paleikat e João Cruz Costa. Editora Abril Cultural, $3^{\text {a }}$ edição. São Paulo, 1983. p. 185-186

PLATÃO. Theaetetus. Tradução de Carlos Alberto Nunes. Editora UFPA, $3^{\text {a }}$ edição revisada. Belém - Pará, 2001.

ROSS, David. Plato's Theory of Ideas. Ed. Oxford University Press. London, 1966. RYLE, Gilbert. Plato's progress. Published by Cambridge University Press, 1966. SANTOS, José Trindade. "Do saber ao conhecimento: O programa da epistemologia platônica". Revista Hypnos, São Paulo, v. 38, $1^{\circ}$ sem., 2017, p. 1-19.

SANTOS, José Trindade. "Linguagem". In: Platão. Organizado por Gabriele Cornelli e Rodolfo Lopes. São Paulo; Portugal: Imprensa da Universidade de Coimbra, $1^{\text {a }}$ edição, 2018. Vários autores. pp.153-166.

SANTOS, José Trindade. "Introdução". In: PLATÃO. Teeteto. Trad. Nogueira, A. M. e Boeri, M. Lisboa: Fundação Calouste Gulbenkian, 3ª Edição, 2010.

SAUNDERS Trevor J. "Ryle (Gilbert): Plato's Progress". In: Revue belge de philologie et d'histoire, tome 45, fasc. 2, 1967. Histoire (depuis l'Antiquité) Geschiedenis (sedert de Ottdhéid) pp. 494-497.

SEDLEY, David. The Midwife of Platonism. Oxford: University Press, 2002.

SÉGUY-DUCLOT, A. Dialogue sur le Théétète de Platon. Paris, Belin, 2008.

SOARES, MÁRCIO. Construção e crítica da teoria das ideias na filosofia de Platão: dos diálogos intermediários à primeira parte do Parmênides. Porto Alegre: Editora PUCRS, 2010.

STERN, P. Knowledge and Politics in Plato's Theaetetus. New York, CUP, 2008.

TRABATTONI, F. “Logos e doxa: o significado da refutação da terceira definição de episteme". In: SANTOS, J. T. (Org). Do Saber ao Conhecimento - Estudos sobre o Teeteto. Lisboa: Centro de Filosofia da Universidade de Lisboa, 2005.

UNTERSTEINER, M. Les sophistes. Seconde édition, trad. fr. A. Tordesillas. Paris: Vrin, 1993.

ZENI, Eleandro Luis. Conhecimento e Linguagem: Um Estudo do Teeteto de Platão. Ed. UFSM. Rio Grande Do Sul (RS), 2012.

Autor(a) para correspondência: Aurelio Oliveira Marques, Universidade de Brasília, Ala Norte -

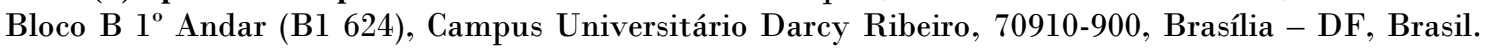
amigos.aurelio@gmail.com

MARQUES, Aurelio Oliveira. A noção de opinião falsa à luz de uma interpretação do não-ser: um problema entre o Teeteto e o Sofista de Platão. Griot : Revista de Filosofia, Amargosa - BA, v.19, n.2, p.122-134, junho, 2019. 